\title{
The Gap of Awareness in Orthodontic Treatment
}

\author{
Yulia Peeva \\ Department of Social Medicine and Public Health, Faculty of Public Health, Medical University of Plovdiv, Plovdiv, Bulgaria \\ Email: julipeeva@abv.bg
}

How to cite this paper: Peeva, Y. (2017) The Gap of Awareness in Orthodontic Treatment. Open Access Library Journal, 4: e3367.

https://doi.org/10.4236/oalib.1103367

Received: January 11, 2017

Accepted: February 10, 2017

Published: February 13, 2017

Copyright (c) 2017 by author and Open Access Library Inc.

This work is licensed under the Creative Commons Attribution International License (CC BY 4.0).

http://creativecommons.org/licenses/by/4.0/ (c) (†) Open Access

\begin{abstract}
The individual's awareness of malocclusion, like the necessity for orthodontic treatment, seems to be different at different ages, as observed in orthodontic referrals. The information originating by orthodontist and proposed to the patient may be filled in writing and in oral form. The contemporary world requires that it can appear on-line, too. The aim of the study is to define the gap of children and parents awareness and motivation for orthodontic treatment. Materials and Methods: We have randomly selected parents $(\mathrm{n}=214)$ and their children $(n=258)$ from Plovdiv at 2012. The inquiry contains questions designed to provide socio-demographic characteristics, the role of orthodontist and both importance of social media for the awareness in orthodontics. Results: Gender is not a factor for the parents awareness on the qualifications and skills of orthodontists $\left(\mathrm{P}>0.05 ; \chi^{2}=4.71, \mathrm{df}=3\right)$ but statistics shows significant difference in the group of orthodontist regarding the necessary motivation of patients $\left(\mathrm{P}<0.05 ; \chi^{2}=12.85\right)$. The benefits are complex and diverse, according to the perceptions of parents $\left(\mathrm{P}<0.05 ; \chi^{2}=29.60\right.$, $\mathrm{df}=1)$. Mothers have a greater awareness than fathers $\left(\mathrm{P}=0.027 ; \chi^{2}=14.23\right.$, $\mathrm{df}=6$ ), but fathers take significant involvement in the payment of orthodontic services. Conclusions: Patient consent may be helpful to anticipate the problems that might arise during treatment. The cooperation of the patient is the only significant factor that orthodontists comply. The benefits of orthodontic treatment are complex and diverse, according to the perceptions of parents.
\end{abstract}

\section{Subject Areas}

Dentistry, Public Health, Sociology

\section{Keywords}

Gap in Orthodontic Awareness, Demand of Treatment, Social Media

\section{Introduction}

Oral health can affect the general health and well-being of humans. Awareness of 
malocclusion and the need to make corrections have increasingly become prevalent among young population. The most contemporary word today in our online world hovers around "social media". Social media has a huge role in communication and the patient can not only be informed. The orthodontists provide information on what is going on in vivo but there are continuous attacks by the media. Upon opening the page in Facebook, a large number of windows and advertising calls follow "Like us on Facebook", "Follow us on Twitter", "Visit our website", and "Watch us on YouTube". According to one of the motivation theories, the protection of patient's health is based on the following factors:

- understanding of the gravity of threatening event;

- understanding the probability of occurrence of threatening event;

- usefulness of the recommended preventive behavior;

- the benefits of personal health [1] [2].

The motivation for defense is an assessment of the probable threat and how to cope with it. Its main function is to encourage the patient to instigate a direct protective behavior.

The parents have the most important role in motivating and obtaining consent from the child for the upcoming treatments according to Jokovic [3]. For other researchers certain negative mood could be predicted and thus can thwart the risk factors for orthodontic treatment. The relationships with orthodontist could be improved, too [4].

Another concept for the gap of orthodontic treatment is informed consent. It defines as "the degree to which the patient's behavior (in terms of taking drugs, the diet or the necessary qualitative changes in lifestyle) coincides with medical or health advice" [5]. Many researchers argue that the term "agreement" builds the image of the patient as a passive and submissive personality, unable to make a choice and therefore prefer alternative conditions (as well as adherence to certain rules already), coordination or cooperation [4] [6] and especially consent, based on awareness. These terms are placing greater emphasis on the role of patient choice and suggest more active cooperation to achieve therapeutic success [7].

\section{Aim}

The aim of the study is to define the gap of children and parents awareness and motivation for orthodontic treatment.

\section{Materials and Methods}

The inquiry contains questions designed to provide socio-demographic characteristics, the role of orthodontist and both importance of social media for the awareness in orthodontics. The Stein formula for calculation the number of units of observation is applied in variation variables with $\mathrm{P}(\mathrm{u})=0.95, \mathrm{Sx}=3.45$, and the maximum error $\Delta=0.5$. The estimated number of units required for children, to obtain a $95 \%$ confidence of the results was 183 . The inquiry card consist 36 questions (open, closed and mixed). The parents have been observed 
for socio-demographic characteristics; the role of general practitioner dentists and school dentists; parents and children attitudes from orthodontic treatment; awareness for orthodontic treatment and financing tools of orthodontic treatment.

To explore health awareness and motivation have been studied children aged 7 to 18 years. Finally, we have randomly selected parents $(n=214)$ and their children $(n=258)$ from Plovdiv and have been study them for orthodontic attitudes in 2012 [5]. The parents have been used different social media to increase the awareness for orthodontic treatment such as Google, Facebook, YouTube, Twitter, websites. All parents have an open access to seek health information on social networks. Data have been processed with nonparametric, alternative and graphical analyses using software (IBM SPSS v.19).

\section{Results}

The family health habits have an influence on the length and number of visits to the dental office in the term of one year. Perceived negative attitude has outlined long time trend, since still there exists a high enough percentage of children who do not like to visit the dentist $(43.30 \% \pm 3.07 \%)$. The children motivation for seeking orthodontic treatment should be defined before the incoming procedures in the mean of mutual satisfaction results in both dentist and child. The opinion about awareness and their expectations for the outcomes of orthodontic treatment was studied among children from 7 to 18 years old. The questions are subordinated on the impact of improved oral health through the everyday life of the patient. Alignment of time series shows a decreasing trend with children of mild deformity $\left(\mathrm{y}_{\mathrm{t}}=-0.247 \mathrm{x}+9.27, \mathrm{r}^{2}=0.03\right)$ and with children of moderate deformation $\left(y_{t}=-0.373 x+9.46, r^{2}=0.087\right)$. Communications will be at the required level if each side understands the expectations of the other. Therefore, the results of interest are posed to the child's question: "Are you worried to ask your dentist?". The distribution of relative shares and how they responded to children's attitudes are presented at Table 1.

It is better that a large number of children $87.98 \% \pm 2.02 \%$ do not bother to ask questions doctors for their health and everything that excites them in the dental office. The patients, who embarrassed to ask, are $5.04 \% \pm 1.36 \%$ but $6.98 \% \pm 1.59 \%$ "can't decide how to answer to this question". Clinical and educational matters determine the behavior of the physician. Who is responsible for

Table 1. Distribution of the children's relative shares for the question "Are you worried to ask the dentist about your oral health?".

\begin{tabular}{|c|c|c|c|c|c|c|c|c|c|c|c|c|}
\hline \multirow{2}{*}{ Gender } & \multicolumn{3}{|c|}{$\begin{array}{l}\text { Willingly visit } \\
\text { dentist }\end{array}$} & \multicolumn{3}{|c|}{$\begin{array}{c}\text { Unwillingly visit } \\
\text { dentist }\end{array}$} & \multicolumn{3}{|c|}{ Unable to decide } & \multicolumn{3}{|c|}{ Total } \\
\hline & $\mathrm{n}$ & $\%$ & $\mathrm{Sp}$ & $\mathrm{n}$ & $\%$ & $\mathrm{Sp}$ & $\mathrm{n}$ & $\%$ & $\mathrm{Sp}$ & $\mathrm{n}$ & $\%$ & $\mathrm{Sp}$ \\
\hline Boys & 65 & 25.19 & 2.70 & 41 & 15.89 & 2.28 & 15 & 5.81 & 1.46 & 121 & 46.90 & 3.11 \\
\hline Girls & 51 & 19.77 & 2.48 & 70 & 27.13 & 2.77 & 16 & 6.20 & 1.46 & 137 & 53.10 & 3.11 \\
\hline Total & 116 & 44.96 & - & 111 & 43.02 & - & 31 & 12.02 & - & 258 & 100.0 & - \\
\hline
\end{tabular}


the children's oral health is the question asked for all of them participated in the survey? The answers are presented visually at Figure 1.

The awareness of parents and their responsibility in initiating and providing treatment has been also analyzed. According to the parents, informed consent is done only by $22.07 \% \pm 2.84 \%$ of them. This form has not been offered to the other respondents $(77.93 \% \pm 2.84 \%)$ which give grounds to conclude that dentists and patients do not know their rights and/or do not want to be informed. The gender distribution of respondent's relative shares to a completed form of informed consent is presented graphically on Figure 2.

A large proportion of parents did not filled out a form of informed consent. For fathers, the relative parts are $64.44 \% \pm 7.14 \%$, similar are these data for mothers $-81.55 \% \pm 2.99 \%$. Evaluating compliance with orthodontic treatment, gender difference was found significant for respondents signed informed consent. According to the data, mothers more often than fathers give their conduct $\left(\mathrm{P}=0.014 ; \chi^{2}=6.04, \mathrm{df}=1\right)$. The result takes into account a negative attitude of the dental practitioners to neglect the declaration of informed consent. Usually, this information can be submitted orally to the patient. It has been compared to the information that patient founded in Internet $\left(\mathrm{P}=0.65 ; \chi^{2}=4.23\right)$.

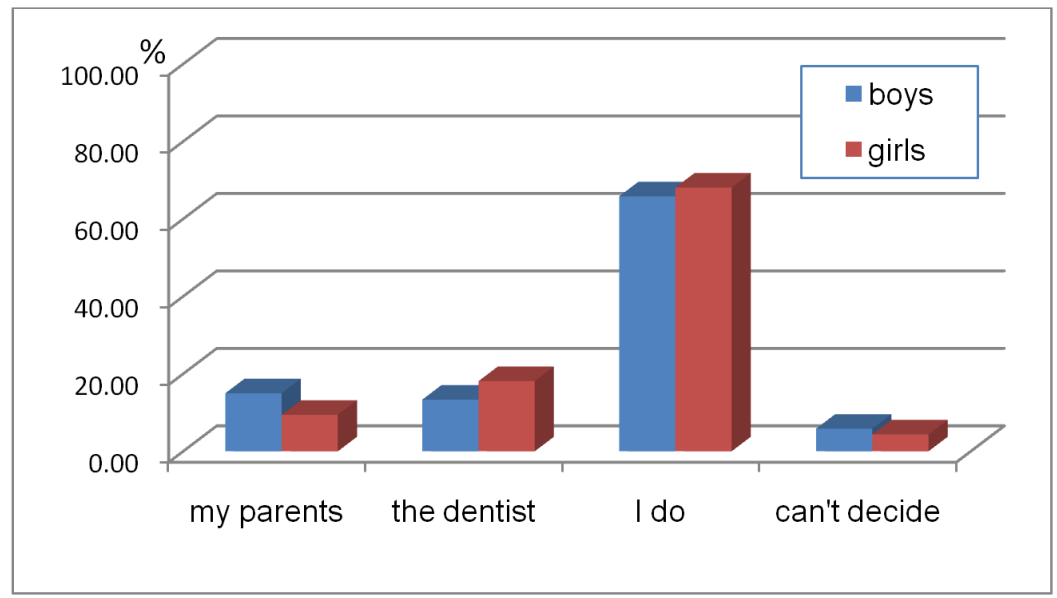

Figure 1. The distribution of answers to the question: "Who is responsible of my oral health?".

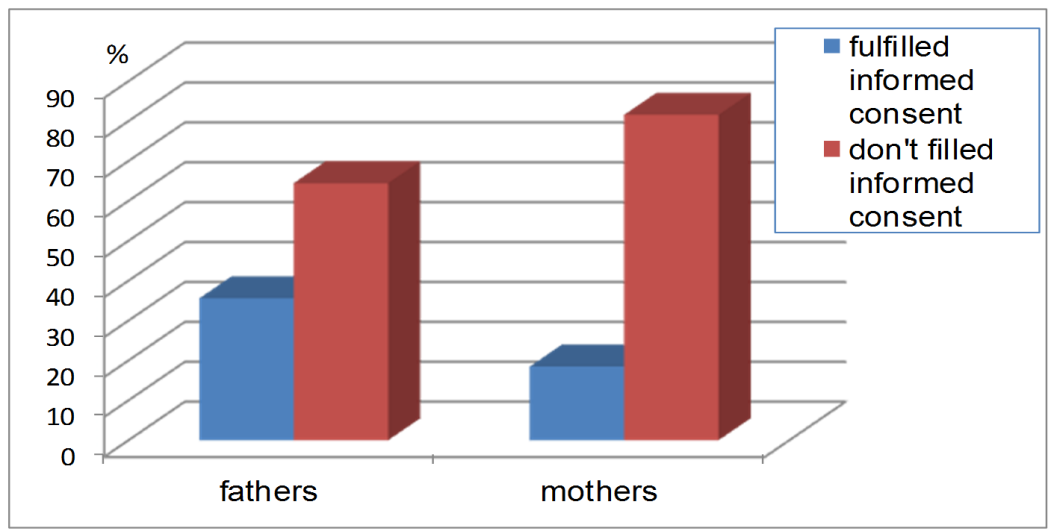

Figure 2. The informed consent importance for parents. 


\section{Discussions}

The discussion of the issue stresses on the importance of awareness of orthodontic treatment. The physiological limits of maxillofacial growth set boundaries for the correctness in respect to socio-medical, socio-economic and psychosocial factors. The family foresight in making decision reflects the direction in which these factors operate. The right time for first consultation is also of importance [2] [8] [9] [10].

The improved dental aesthetics is fundamental to the future realization of a child in the society. The high demand for timely prevention of tooth and jaw deformities and extreme precision available through new technologies and methods allow to improve the ratios between the teeth, lips and jaws and to harmonize the facial features [11] [12].

The analysis of orthodontic health insurance for children in Europe shows a lack of participation of the Bulgarian authorities [13]. There exists a crisis in the postgraduate training of specialists that, along territorial and financial access, define the high incidence of untreated cases. Neither the National Health Insurance Fund, nor the private health insurance covers the costs of orthodontic treatment. Patients pay for everything [9].

Awareness, benefits and expectations of the child for orthodontic treatment:

Evaluation of the awareness of children is necessary not to allow differences in expectations about the outcome of orthodontic treatment between patient and doctor. One of the most common words in today's on-line world is "social media". The mass media are important in communication, because through them the patient can be informed and also can obtain information. This process of exchange of innovations and significant facts is not connected in any way with pain or discomfort. There is a great advantage for patients if orthodontists provide information about their event online at the moment.

Statistics show that orthodontists and dentists will no future without its own blog or media presence [14]. Although this type of advertising is banned in the country and the limited number of articles on the issue, there is feedback from many dentists that invested-time, effort and money on their part are justified [15]. The media play a role in the development of dental practices in some countries. They support the formation of lasting and sustainable relationships with patients, reinforcing the credibility of the dentist.

Modern users require information about the products and services they enjoy. If the survey was conducted before 2000, issues the card would be limited to the following:

12. Do you accept dentist as a friend?

13. Do you worry to ask questions your doctor?

15. Who is responsible for the health of your teeth?

Today, issues related to awareness of child look like this:

16. Do you use the Internet to get information on orthodontic treatment?

17. Which better known media informed about dental and jaw problems and 
their treatment?

\section{Was this information useful for you?}

Relationships "dentist-child" are particularly important for the moral outlook of the dental practice, and the child is at the center of attention ever. Communication is at the right level, if both parties know in advance what the expectations of the other are.

The improvement of the oral health and psycho-social status through timely information and motivation are the benefits sought by the orthodontic treatment.

\section{Conclusions}

In conclusion, the present study demonstrates the influence of the closest to the individual environments. The impact of the family, school and orthodontist should be phased, adaptive and rational. When it is done without coercion, this is the personal choice of the child for orthodontic treatment.

The cooperation is the only significant factor that orthodontists comply.

Mothers have a greater awareness than fathers who take significant involvement in the payment of orthodontic services.

The benefits of orthodontic treatment are complex and diverse, according to the perceptions of parents.

\section{References}

[1] Baldwin, D. and Barnes, M. (1965) Psychosocial Factors Motivating Orthodontic Treatment. IADR, 461.

[2] Josefsson, E., Bjerklin, K. and Lindsten, R. (2009) Factors Determining Perceived Orthodontic Treatment Need in Adolescents of Swedish and Immigrant Background. European Journal of Orthodontics, 31, 95-102. https://doi.org/10.1093/ejo/cjn069

[3] Jokovic, A., Locker, D., Stephens, M., Kenny, D., et al. (2002) Validity and Reliability of a Questionnaire for Measuring Child Oral-Health Related Quality of Life. Journal of Dental Research, 81, 459-463. https://doi.org/10.1177/154405910208100705

[4] Abbott, F. and Abbott, N. (2015) Esthetics and Psychology. Esthetic Dentistry, 532542. https://doi.org/10.1016/B978-0-323-09176-3.00037-1

[5] Feldmann, I., List, T., John, M., et al. (2007) Reliability of a Questionnaire Assessing Experiences of Orthodontic Treatment in Adolescents. Angle Orthodontist, 77, 311-317. https://doi.org/10.2319/0003-3219(2007)077[0311:ROAQAE]2.0.CO;2

[6] Feu, D., de Oliveira, B., et al. (2010) Oral Health-Related Quality of Life and Orthodontic Treatment Seeking. American Journal of Orthodontics and Dentofacial Orthopedics, 138, 152-159. https://doi.org/10.1016/j.ajodo.2008.09.033

[7] Hassan, A. and Amin, H. (2010) Association of Orthodontic Treatment Needs and Oral Health-Related Quality of Life in Young Adults. American Journal of Orthodontics and Dentofacial Orthopedics, 137, 42-47.

https://doi.org/10.1016/j.ajodo.2008.02.024

[8] Lewit, D. and Virolinen, K. (1968) Conformity and Independence in Adolescents' Motivation for Orthodontic Treatment. Journal of Child Development, 39, 1189- 
1200. https://doi.org/10.2307/1127283

[9] Peeva, Yu. (2010) An Orthodontic Manpower for 10-Years Period in Plovdiv Region. Public Health and Health Care in Greece and Bulgaria: The Challenge of the Cross-Border Collaboration, 127-137.

[10] Bos, A., Hoogstraten, J. and Andersen, B. (2007) Attitudes towards Orthodontic Treatment: A Comparison of Treated and Untreated Subjects. European Journal of Orthodontics, 27, 148-154. https://doi.org/10.1093/ejo/cjh071

[11] Proffit, W., Fields, H., et al. (2000) Orthodontic Treatment Planning: From Problem List to Specific Plan. In: Contemporary Orthodontics, 3rd Edition, Mosby, Inc., S. Louis, 209.

[12] Cash, T. and Fleming, E. (2000) Body Image and Social Relations, Guilford, NY, 277-286.

[13] Katrova, L. (2010) Ethical, Legal, and Professional Foundations of the Autonomous Regulation of the Dental Profession, the Case of Bulgaria. Journal of IMABAnnual Proceeding, 16, 70-76.

[14] Pithon, M., Nascimento, C., et al. (2014) Do Dental Esthetics Have Any Influence on Finding a Job? American Journal of Orthodontics and Dentofacial Orthopedics, 146, 423-429. https://doi.org/10.1016/j.ajodo.2014.07.001

[15] Bhamrah, G., Ahmad, S. and NiMhurchadha, S. (2015) Internet Discussion Forums, an Information and Support Resource for Orthognathic Patients. American Journal of Orthodontics and Dentofacial Orthopedics, 147, 89-96.

https://doi.org/10.1016/j.ajodo.2014.08.020

Open Access Library

Submit or recommend next manuscript to OALib Journal and we will provide best service for you:

- Publication frequency: Monthly

- 9 subject areas of science, technology and medicine

- Fair and rigorous peer-review system

- Fast publication process

- Article promotion in various social networking sites (LinkedIn, Facebook, Twitter, etc.)

- Maximum dissemination of your research work

Submit Your Paper Online: Click Here to Submit

Or Contact service@oalib.com 